\title{
Reform of the Irish family courts system
}

\author{
Rosemary O'Sullivan
}

Faculty of Law, UCC

\section{Introduction}

Access to the law and to the courts is an essential part of the rule of law in any democratic society. This right must not be 'theoretical or illusory' but rather should be 'practical and effective' as declared by the European Court of Human Rights in Airey $v$ Ireland [1979] 2 E.H.R.R. 305.

Ireland's family law courts are in serious need of reform. Delays are problematic, the system is expensive and the courts do not appear to operate efficiently or coherently. Concerns have also been expressed at the continuing use of an adversarial model in this sensitive and complex area of law. Due to concerns that the current family court system is not fit for purpose, the Government has promised reform. The aim of my research is to develop a model of Irish family law courts drawing on international experience with a view to supporting progressive reform in this area.

\section{Why are the family courts in need of reform?}

Family law presents enormous challenges. Disputes arising out of family breakdown are as complicated and emotionally charged as they are common. Increasing numbers of people find themselves forced, by financial circumstances, to make their way without legal representation through a process designed for lawyers. A small number of these people go to trial on their own. Many settle, whether or not they have the information and support they need; some walk away, their conflict unresolved and possibly giving up what they need or were entitled to. Others never approach the family court system in the first place, seeing it as inaccessible, unaffordable and unresponsive to their circumstances.

While some people who use the court system to resolve their family law issues are satisfied with the result, the court process itself could be improved. At present, different aspects of a family dispute are sometimes being dealt with at the same time in different courts. This process denies any one court the opportunity to view the problem as a whole. Also, it causes duplicated efforts by judges, lawyers, witnesses, court administrators and the parties themselves and this naturally leads to increased costs. 
Another issue that is repeatedly raised is the lack of specialist training that judges receive in dealing with vulnerable parties, in particular children. Judges presiding over family law cases have not necessarily practiced in the field of family law prior to their appointment and are not appointed specifically as family law judges. In contrast, judges in the New Zealand Family Court are specifically chosen because of their aptitude for family law work and only judges that are suitable to deal with matters of family law by reason of their training, experience and personality are appointed to the Family Court in Australia.

In addition, there is an ever increasing volume of cases coming before the courts administering family law. Despite family cases often constituting the highest percentage of cases on the civil calendars, they receive insufficient allocation in the scheduling of court sitting, resulting in long delays in cases being heard. The drafters of the Constitution could never have anticipated the growth in the volume of litigation, its complexity and diversity, throughout the legal system. As Denham J. pointed out in 2012 at the UCD Constitutional Studies Group Conference on "The Irish Constitution: Past, Present and Future":

"Litigation reflects the radical changes in society which have occurred in Ireland in the last 75 years, especially in the last 25 years. Therefore, the court structure required [now] is different to that of 1937."

In light of the above difficulties, the Programme for Government 2011-2016 commits to the introduction of a constitutional amendment to allow for the establishment of a distinct and separate system of family courts to streamline family law court processes and make them more efficient and less costly, as soon as resources as permit. The specifics of the proposed reforms are as yet unknown. Indeed, the concept of a family court in itself embraces a wide range of ideas. In addition to the physical environment in which a family court is held and how its proceedings are organised, establishment of a family court system requires ancillary services, procedures and supports to be put into place to ensure, for example, the use of alternative methods of dispute resolution outside of the formal court system.

\section{The Aim of my Research}

This project will first analyse Irish law (including Constitutional Law) and the obligations under the European Convention on Human Rights associated with family courts and the rights of the parties in family law proceedings. With this legal framework in place, the research will then move on to documenting concerns with the existing courts. This will involve using existing literature and empirical research methodologies (court observation and semi structured interviews with professionals working in the family law area and litigants). It will then use this information to consider what reforms are necessary to enhance the court's accessibility, effectiveness and integration of services in line with international experience and standards. For the purpose of this project: accessibility means simplified 
procedures, and services that are affordable and available within a reasonable time and distance. Effectiveness means that appropriate services are matched to family members' needs; that services promote timely, fair and lasting resolution of disputes, and that they foster functional family relationships. Integration means minimizing overlaps and gaps in services and linking those services so users can move easily from one service to another as appropriate. Furthermore, it means that providers of family justice services share common objectives and co-operate in planning and delivering those services.

It will also examine the family courts in other common law jurisdictions, including those currently undertaking similar reforms - notably England and Wales, Australia and New Zealand. The study will examine these family courts in order to identify possible models for achieving accessibility, effectiveness and integration of services in Ireland. Over the past number of years, these jurisdictions have come to the conclusion that the adversarial system is not best suited to family law, and have been exploring alternatives focused on the needs of the children and designed to minimise the conflict between the parties. This has involved greater specialisation in the family law area, including alternative forms of dispute resolution, and, for especially intractable cases, putting in place specialised family courts with specialist judges, supported by trained specialists from other disciplines.

Finally, this information and analysis will be used to develop a family court model consistent with Ireland's legal framework, including the Constitution and the European Convention on Human Rights. The practical realities of setting up such a specialist system in a small jurisdiction will also be explored along with the challenge of changing the culture of the family justice system. In this way, the research will identify key values, standards and principles necessary to underpin the new family court model and how they might be implemented in practice. This project will aim to recommend a family court that will:

be accessible

use available resources efficiently and effectively

integrate service planning and delivery

ensure children's welfare by adopting a uniform approach and procedure to hearing the child's voice. Facilities for the courts to interview children in family law cases must be provided for those children who have attained a sufficient age and maturity.

promote early resolution of disputes, and minimize conflict by encouraging early cooperative settlement, refining and enhancing non-adversarial settlement processes, and supporting trials as an appropriate recourse only when other means are not appropriate or effective.

Rosemary O'Sullivan is a PhD student in the Faculty of Law, under the supervision of Professor Ursula Kilkelly. This research has been funded by the UCC Law Graduate School Fellowship 
and the Government of Ireland Postgraduate Scholarship, awarded by the Irish Research Council. 